\title{
Concentrations of Nicotinamide Nucleotide Coenzymes in Micro-Organisms
}

\author{
BY J. LONDON* AND M. KNIGHT \\ Department of Microbiology and A.R.C. Unit for Microbiology, \\ The University, Sheffield 10
}

(Received 16 December 1965)

\section{SUMMARY}

The results are presented of a survey of NAD and NADP concentration in twenty micro-organisms. They fell into three categories with respect to NAD concentration. (i) High NAD ( $>4.5 \mu$ moles/g. dry weight) in obligate anaerobes, members of the Lactobacillaceae and Saccharomyces cerevisiae. (ii) Medium NAD (1.0--3.0 $\mu$ moles/g. dry weight) in faculative anaerobes, photosynthetic bacteria and Nocardia globerula. (iii) Low NAD ( $<\mathbf{0 . 9} \mu \mathrm{moles} / \mathrm{g}$. dry weight) in obligate aerobes.

Different categories were not found with respect to NADP concentration.

Consistent differences in NAD concentration due to conditions of aeration were not found, but growth on different substrates frequently led to changes in NAD concentration. The concentration of NAD in Streptococcus faecalis grown on gluconate was only $6 \%$ of the concentration in glucose-grown organisms. In Pseudomonas oxalaticus NAD concentrations when grown on formate or oxalate were 13 and 8 times, respectively, greater than the concentration in acetate-grown organisms.

NADP concentrations in Leuconostoc mesenteroides and Streptococcus faecalis were increased 2- to 5 -fold by aeration. In Nocardia globerula, Streptomyces griseus and Bacillus megaterium the concentrations of NAD found after growth in complex media were 3-5 times greater than the amounts found after growth on minimal media. This effect was not observed with Pseudomonas fluorescens.

\section{INTRODUCTION}

Although there is a substantial amount of information on the concentrations of nicotinamide nucleotide coenzymes in animal tissues (see Greenbaum, Clark \& McLean, 1965), relatively little is known of the concentrations in micro-organisms. Kaplan (1960) published, for $\mathrm{NAD}^{+}$and $\mathrm{NADP}^{+}$concentrations in eight species of micro-organism, figures which show certain tendencies. $\mathrm{NAD}^{+}$is almost always present in larger quantities than NADP+. The concentrations of coenzyme in the four faculative anaerobes (Escherichia coli, Aerobacter aerogenes, Photobacterium fischeri, Proteus vulgaris) are all of the same order and are a little below the figure for Saccharomyces cerevisiae. The amounts found in the strict aerobes (Pseudomonas fluorescens, Azotobacter agile, Mycobacterium butyricum) are much lower than those found in the faculative anaerobes.

Takebe \& Kitahara (1963) estimated the concentrations of nicotinamide

* Present address: Department of Bacteriology, University of California, Berkeley, California, U.S.A. 
nucleotide coenzymes in a variety of micro-organisms, mainly lactic acid bacteria. They did not observe the striking differences between strict aerobes and facultative anaerobes reported by Kaplan (1960), but they did find very high values for NAD among the lactic acid bacteria. They also found that there were significant differences between homofermentative and heterofermentative species; in general, NAD concentrations were higher and NADP concentrations lower in homofermentative species. Takebe \& Kitahara (1963) also found that conditions of aeration and variations in substrate affected the NAD concentrations in Escherichia coli, Lactobacillus plantarum and Saccharomyces cerevisiae when growing on complex media.

The work of Kaplan (1960) and of Takebe \& Kitahara (1963) suggested that there might be significant differences in nicotinamide nucleotide coenzyme concentrations between bacteria of different physiological types, and that the concentrations of these coenzymes might be affected by nutritional and cultural conditions. The present results are derived from a survey of NAD and NADP concentrations in a variety of micro-organisms made to confirm and extend the work of Kaplan (1960) and of Takebe \& Kitahara (1963), and to find whether any physical or biochemical factors influence the intracellular concentrations of these enzymes.

\section{METHODS}

Micro-organisms, media and cultural conditions

Unless stated otherwise, cultures of all the micro-organisms used in this study were taken from the collection kept in this department.

Bacillus cereus (obtained from the Department of Bacteriology, University of Sheffield) was maintained on slopes of PMG agar (g./l.: peptone, 10.0; Marmite, 3.0; glucose, $10 \cdot 0 ; \mathrm{NaCl}, 5 \cdot 0$; agar, 10.0) and grown on the following medium: (g./1.) Difco peptone, $2 \cdot 0 ;$ Marmite, $1 \cdot 0 ; \mathrm{NaCl}, 10 \cdot 0$; glucose, $10 \cdot 0$ or sodium acetate trihydrate, $\mathbf{1 0} \cdot \mathbf{0}$.

Bacillus megaterium was maintained on slopes of PM agar (g./l.: peptone, 10.0; Marmite, 3.0; $\mathrm{NaCl}, 5 \cdot 0 ;$ agar, 10.0) and grown on the following medium(Holland, 1961; g./l.) : $\mathrm{NH}_{4} \mathrm{Cl}, 1 \cdot 0 ; \mathrm{KH}_{2} \mathrm{PO}_{4}, 0 \cdot 3 ; \mathrm{K}_{2} \mathrm{HPO}_{4}, 0.7 ; \mathrm{Na}_{2} \mathrm{SO}_{4}, 0 \cdot 1 ; \mathrm{L}$-glutamate, $0.5 ;$ glucose, $10 \cdot 0 ;$ (mg./l.) $\mathrm{MgSO}_{4} .7 \mathrm{H}_{2} \mathrm{O}, 40 ; \mathrm{MnSO}_{4} .7 \mathrm{H}_{2} \mathrm{O}, 5 ; \mathrm{CaCl}_{2} .2 \mathrm{H}_{2} \mathrm{O}, 2 ; \mathrm{FeSO}_{4} \cdot 7 \mathrm{H}_{2} \mathrm{O}, 2$.

Bacillus subtilis obtained from the Department of Bacteriology, University of Sheffield, was maintained on PM agar slopes and grown on the acetate medium used for B. cereus:

Chlorobium thiosulphatophilum (National Collection of Industrial Bacteria) NCIB 8327 was maintained and grown on the thiosulphate medium of Larsen (1952).

Clostridium pasteurianum strain w-5 (originally obtained from Dr R. S. Wolfe, University of Illinois, Urbana, U.S.A.) was maintained by weekly transfer on $10 \mathrm{ml}$. tubes of potato broth medium (Jensen \& Spencer, 1947). For estimation of coenzymes, C. pasteurianum was grown on $500 \mathrm{ml}$. quantities of the ammonium sulphate medium of Carnahan \& Castle (1958) as modified by Lovenberg, Buchanan \& Rabinowitz (1963), but with glucose (7.5 g./1.) instead of sucrose.

Clostridium welchii strain SR 12 was maintained on Robertson's meat medium (Oxo Ltd., London, E.C.4) and grown on the following medium: (g./l.) Robertson's 
meat medium, 2 tablets; Oxoid tryptone, 20.0; Oxoid Lab Lemco, 2.0; glucose $10 \cdot 0$; (mg./l.) pyridoxine $\mathrm{HCl}, 10$.

Escherichia coli strain 4071 was maintained on PM agar slopes and grown on the following media: a. Complex: (g./l.) Oxoid tryptone, 10.0; Difco yeast extract, $10.0 ; \mathrm{K}_{2} \mathrm{HPO}_{4}, 0.5$; glucose, $3.0 ; b$. Minimal: (g./l.) $\mathrm{MgSO}_{4} .7 \mathrm{H}_{2} \mathrm{O}, 0.2 ; \mathrm{NH}_{4} \mathrm{Cl}, \mathbf{2} \cdot 0$; $\mathrm{Na}_{2} \mathrm{HPO}_{4}, 6 \cdot 0 ; \mathrm{KH}_{2} \mathrm{PO}_{4}, 3 \cdot 0 ; \mathrm{NaCl}, 3 \cdot 0$. In experiments where growth was limited by substrate, the amounts of substrate added were: glucose, $570 \mathrm{mg} . / 1$., or succinic acid (neutralized by addition of $\mathrm{NaOH}$ ) $750 \mathrm{mg}$./l. To ensure that oxygen did not become limiting, these amounts were calculated from the aerobic growth yields for $E$. coli determined by Whitaker (1961) to give a final $E_{610 \mathrm{~m} \mu}$ of $0 \cdot 6$. In aerobic experiments where growth was not limited by substrate, or in anaerobic experiments, the glucose concentration was $10 \mathrm{~g}$./l. c. Defined complete medium (S. R. Elsden, personal communication). The amino acid composition of this medium is based on the amino acid composition of Escherichia coli determined by Roberts et al. (1955). The medium contains in mg./l. medium $b$ (above): aspartate, 206; lysine $\mathrm{HCl}, 199$; methionine, 79 ; threonine, 86 ; isoleucine, 94; glutamate, 242; proline, 83; arginine $\mathrm{HCl}, 177$; serine, 100 ; glycine, 93.5 ; cysteine $\mathrm{HCl}, 41$; alanine, 176 ; valine, 100; leucine, 161 ; tyrosine, $59 \cdot 6$; phenylalanine, 84 ; tryptophan, 33 ; histidine $\mathrm{HCl}$, $28 \cdot 8$; adenine, 81 ; guanine, 109 ; cytosine, 53.5 ; uracil, 47 ; thymine, $11 \cdot 4$; thiamin $\mathrm{HCl}, 0.5$; pyridoxine $\mathrm{HCl}, 0.5$; calcium pantothenate, 0.5 ; riboflavin, 0.5 ; nicotinic acid, $1 \cdot 0 ; p$-aminobenzoic acid, $0 \cdot 1$; biotin, 0.001 ; folic acid, 0.01 .

Leuconostoc mesenteroides was maintained on PMG agar slopes, and grown on the medium of Takebe \& Kitahara (1963) with glucose as substrate.

Leucothrix mucor (obtained from Dr 'T. Brock, Department of Bacteriology, University of Indiana, Bloomington, Indiana, U.S.A.) was maintained and grown on the media of Brock (1964).

Micrococcus denitrificans (Verhoeven strain; obtained from Dr J.G. Morris, Department of Biochemistry, University of Leicester) was maintained on the medium described by Kornberg, Collins \& Bigley (1960) and grown on the medium of Kornberg (1958) with glycerol $\left(5 \cdot 0 \mathrm{ml}\right.$./l.) as carbon source, and with $\left(\mathrm{NH}_{4}\right)_{2} \mathrm{SO}_{4}$ $(5 \cdot 0 \mathrm{~g} . / \mathrm{l}$.$) as nitrogen source instead of ammonium acetate.$

Nocardia globerula ( (СIB 8852) was maintained on PM agar slopes and grown on: $a$, the complex medium of Krebs \& Bellamy (1960) or, $b$, the defined medium of Mencher \& Heim (1962).

Peptostreptococcus elsdenii strain LC 1 was maintained and grown on the media described by Walker (1958).

Pseudomonas fuorescens strain $\mathrm{kB} 1$ was maintained on $\mathrm{PM}$ agar slopes and grown on the following media: $a$, minimal: (g./l.) $\left(\mathrm{NH}_{4}\right)_{2} \mathrm{SO}_{4}, 0.5 ; \mathrm{KH}_{2} \mathrm{PO}_{4}, 10 \cdot 0$; nitrilotriacetic acid, $\mathbf{1} \cdot \mathbf{0}$; substrate (glucose or sodium succinate), $5 \cdot 0$; stock salt solution (Bauchop \& Elsden, 1960), $1 \cdot 0 \mathrm{ml}$. The $\mathrm{pH}$ was adjusted to $7 \cdot 0$ with $\mathrm{NaOH}$. $b$, Complex: (g./l.) peptone, 10.0; Marmite, $3 \cdot 0 ; \mathrm{NaCl}, 5 \cdot 0$; succinic acid, $15 \cdot 0 ; \mathrm{NaOH}$ to $\mathrm{pH} 6 \cdot 6$.

Pseudomonas oxalaticus strain ox 1 was maintained on PM oxalate (5 mM) agar slopes. It was grown on the medium of Johnson, Jones-Mortimer \& Quayle (1964) with $100 \mathrm{~mm}$ formate, oxalate or acetate as substrate.

Pseudomonas saccharophila (obtained from Dr M. Doudoroff, Department of Bacteriology, University of California, Berkeley, California, U.S.A.), was maintained 
and grown on the following medium: (g./l.) $\mathrm{KH}_{2} \mathrm{PO}_{4}, 2 \cdot 32 ; \mathrm{Na}_{2} \mathrm{HPO}_{4}, 6 \cdot 25 ; \mathrm{NH}_{4} \mathrm{Cl}$, $\mathbf{1} \cdot \mathbf{0} ; \mathrm{MgSO}_{4} \cdot \mathbf{7 \mathrm { H } _ { 2 }} \mathrm{O}, 0.5$; ferric ammonium citrate, $0 \cdot \mathbf{1} ; \mathrm{CaCl}_{2}, 0 \cdot 01$; starch, $2 \cdot 5$. (M. Doudoroff, personal communication).

Rhodospirillum rubrum strain 1.1.1 and Rhodopseudomonas palustris strain 2.1.7 (both obtained from Dr J. Lascelles, Department of Biochemistry, University of Oxford) were maintained and grown on the malate + glutamate media of Lascelles (1959).

Saccharomyces cerevisiae was maintained on PMG agar slopes and grown at $30^{\circ}$ on the following media: $a$, PMG; $b$, minimal: (g./l.) $\mathrm{KH}_{2} \mathrm{PO}_{4}, 1 \cdot 0 ;\left(\mathrm{NH}_{4}\right)_{2} \mathrm{SO}_{4}$, 0.5 ; glucose, $10 \cdot 0$; nitrilotriacetic acid, $1 \cdot 0$; inorganic salt solution $\mathrm{B}$ (Barton-Wright, 1946), 10.0 ml.; vitamin solution (Wickerham, 1951), $10.0 \mathrm{ml}$.

Streptococcus faecalis (National Collection of Type Cultures) NCTC 6782 was maintained on PMG agar slopes. Cultures for estimating coenzymes were grown on the complex medium of Takebe $\&$ Kitahara (1963) with either glucose (20.0 g./l.) or gluconate $(3 \cdot 0 \mathrm{~g} . / \mathrm{l}$.) as substrate.

Streptomyces griseus NCTC 7807 was maintained on PMG agar slopes and grown on: $a$, PMG; $b$, the medium of Mencher \& Heim (1962).

Three cultures of each organism studied were always grown, harvested and extracted simultaneously. With some exceptions, it was found that the yield of bacterial paste from $300 \mathrm{ml}$. medium contained enough coenzyme for measurement under the conditions described below. Apart from the exceptions mentioned below, cultures were harvested $12-15 \mathrm{hr}$ after inoculation. The lactic acid bacteria were grown at $37^{\circ}$, the photosynthetic bacteria at $26^{\circ}-29^{\circ}$; all others at $30^{\circ}$.

Anaerobic cultures of Clostridium pasteurianum, C. welchii, Escherichia coli, Leuconostoc mesenteroides, Peptostreptococcus elsdenii, Saccharomyces cerevisiae and Streptococcus faecalis were grown in $\mathbf{5 0 0} \mathrm{ml}$. florence flasks. The obligate anaerobes were grown under an atmosphere of $\mathrm{H}_{2}$, the facultative anaerobes under $\mathbf{N}_{2}$.

Aerobic cultures of Leuconostoc mesenteroides, Saccharomyces cerevisiae and Streptococcus faecalis and of Escherichia coli in which substrate was not limiting, as well as all cultures of Bacillus cereus, B. subtilis, B. megaterium, Pseudomonas fuorescens and $\boldsymbol{P}$. saccharophila, were grown in penicillin flasks which were agitated on a shaker with a rocking action. The rate of shaking was 40 strokes $/ \mathrm{min}$., with an amplitude of $20 \mathrm{~cm}$.

Cultures of Escherichia coli grown aerobically on limited substrate, of Pseudomonas fluorescens grown on complex medium, and all cultures of P. oxalaticus, Micrococcus denitrificans, Streptomyces griseus and Nocardia' globerula, were grown in 2 l. conical flasks, shaken at 200 strokes/min through a 1 in. circle in a Gyrotory incubator-shaker (Model G-25; New Brunswick Scientific Co., New Brunswick, New Jersey, U.S.A.). With $\boldsymbol{P}$. oxalaticus grown on formate or oxalate, where growth was limited by increasing $\mathrm{pH}$ value as the substrate was used, $600 \mathrm{ml}$. medium were used to give sufficient bacteria.

Rhodospirillum rubrum and Rhodopseudomonas spheroides were grown for $36 \mathrm{hr}$ in 1 1. Roux bottles in the light as described by Hoare (1963).

Leucothrix mucor was grown in 1 l. conical flasks on a Griffin wrist-action shaker (Griffin \& George Ltd., Wembley, Middlesex). 


\section{Reagents}

NAD, NADP (sodium salt), glucose-6-phosphate (disodium salt), alcohol dehydrogenase (yeast), glucose-6-phosphate dehydrogenase (yeast), and glutamic dehydrogenase (bovine liver) were brought from Boehringer Corporation (London) Ltd., London, W.5. 2-Oxoglutaric acid was obtained from Koch-Light Laboratories, Colnbrook, Buckinghamshire. All other reagents were Analar, or of comparable purity.

\section{Extraction of nicotinamide coenzymes}

The procedure finally adopted, based on the methods of Bassham et al. (1959) and Takebe \& Kitahara (1963), was as follows. The bacteria were harvested in a refrigerated centrifuge (15-20 min. at 5400 g) and washed once with one-fifth of the original culture volume of ice-cold $50 \mathrm{~mm}$ phosphate buffer $\left(\mathrm{pH} 7 \cdot 0 ; \mathrm{KH}_{2} \mathrm{PO}_{4}+\mathrm{KOH}\right.$ mixture). The bacterial pellet was resuspended in 7-10 ml. $0 \cdot 1 \mathrm{M}$ tris buffer, pH 8.2. Samples of this suspension were then taken to determine dry weight of organism. In the case of Escherichia coli, Pseudomonas oxalaticus and Micrococcus denitrificans, where curves relating extinction at $610 \mathrm{~m} \mu\left(E_{610}\right)$ to dry weight already existed, dry weight was determined from the $E_{610}$ reading of a diluted sample, measured in a Unicam SP 600 spectrophotometer. In the other cases, the bacteria in the sample were washed twice with water by centrifugation, resuspended in water, transferred to a tared weighing bottle and dried at $105^{\circ}$ to constant weight.

The oxidized forms of the coenzymes were extracted by treatment with acid, the reduced forms by treatment with alkali. Acid and alkaline extraction was performed by adding $\mathrm{HCl}(1.5 \mathrm{ml} .0 .33 \mathrm{~N})$ or $\mathrm{NaOH}(1.5 \mathrm{ml} .0 .33 \mathrm{~N})$, respectively, to the suspensions, $\left(3.0 \mathrm{ml}\right.$.) in $20 \times 150 \mathrm{~mm}$. tubes. After incubation at $50^{\circ}$ for $10 \mathrm{~min}$., the extract was cooled to $0^{\circ}$ and neutralized cautiously with either $0.45 \mathrm{ml}$. of $\mathrm{N}-\mathrm{NaOH}$ or $0.45 \mathrm{ml}$. of $\mathrm{N}-\mathrm{HCl}$. In order to avoid local high concentrations, the acid or alkali was added at about $10 \mu \mathrm{l}$./sec., while the extract was stirred vigorously with a length of flexible polyethylene rod $(3 \mathrm{~mm}$. diam.) attached to an overhead stirrer. The neutralized extracts were centrifuged at $23,000 \mathrm{~g}$ for $15 \mathrm{~min}$. to remove insoluble material.

The oxidized forms of the coenzymes, extracted with acid, were then estimated by one of the methods described below. Before estimation, the reduced forms of both coenzymes (extracted with alkali) were oxidized enzymically by adding $10 \mu \mathrm{l}$. 2-oxoglutarate $+\mathrm{NH}_{4} \mathrm{Cl}$ solution (containing $146 \mathrm{mg}$. 2-oxoglutarate and $53 \cdot 5 \mathrm{mg}$. $\mathrm{NH}_{4} \mathrm{Cl} / \mathrm{ml}$., adjusted to $\mathrm{pH} 7 \cdot 0$ with $\mathrm{N}-\mathrm{NaOH}$ ) and $10 \mu \mathrm{l}$. glutamic dehydrogenase

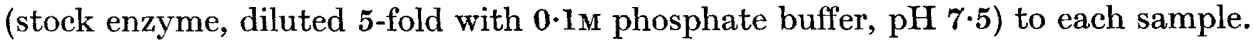
After $15 \mathrm{~min}$. at room temperature, $0 \cdot 1 \mathrm{ml} .5 \mathrm{~N}-\mathrm{HCl}$ was added to each tube, and the extracts incubated $15 \mathrm{~min}$. at $50^{\circ}$ to destroy enzyme. The extract was then neutralized by adding $0.09 \mathrm{ml} .5 \mathrm{~N}-\mathrm{NaOH}$, with the precautions described above and, when necessary, clarified by centrifuging for $15 \mathrm{~min}$. at $23,000 \mathrm{~g}$.

The reliability of the extraction procedure was established by submitting standard solutions of oxidized and reduced forms of both coenzymes to the extraction procedure and measuring the recovery of the coenzymes spectrophotometrically (see below). The \% recoveries were as follows: $\mathrm{NAD}^{+}, 98 ; \mathrm{NADH}, 96 ; \mathrm{NADP}^{+}, 98$; and NADPH, 94. Further, it was shown that any reduced coenzyme present was 
completely destroyed by acid extraction, and that the oxidized forms were destroyed during alkaline extraction.

Effect of extraction conditions on recovery of coenzymes. In preliminary experiments with Saccharomyces cerevisiae, by the procedure of Takebe \& Kitahara (1963) it was found that the period of extraction was critical. Unless the extraction was carried out with extreme care, significant amounts of NAD were destroyed (Fig. 1). Since adequate regulation, both of temperature and of time of exposure of the bacterial, suspensions to heat under conditions 'near boiling' was difficult, the possibility of extracting the coenzymes at lower temperatures was investigated, and $50^{\circ}$ was finally chosen as the extraction temperature. A time course of the release of NAD and NADP from $S$. cerevisiae, using the conditions of acid extraction described above, is shown in Fig. 2. Release of $\mathrm{NAD}(\mathrm{P})$ was complete in $8 \mathrm{~min}$.; $10 \mathrm{~min}$. was chosen as the standard time of extraction. There was no detectable loss of NAD(P) when the extraction time was extended to $15 \mathrm{~min}$.

Some preliminary experiments were also done on the optimum concentration of acid for NAD extraction. The results are given in Table 1 . The acid concentration chosen (equivalent to $0.5 \mathrm{ml} . \mathrm{N}-\mathrm{HCl}$ in $4.5 \mathrm{ml}$. extract) was that giving maximum extraction at minimum acid concentration. The concentration of $\mathrm{NaOH}$ used in the alkaline extraction was chosen arbitrarily.

Table 1. Effect of acid concentration on extraction of NAD from Saccharomyces cerevisiae

\begin{tabular}{|c|c|c|c|}
\hline $\begin{array}{l}\text { N-HCl added } \\
(\mathrm{ml} .)\end{array}$ & $\begin{array}{c}\text { Final HCl } \\
\text { concentration } \\
(\mathrm{mN})\end{array}$ & $\begin{array}{c}\text { Final pH } \\
\text { value }\end{array}$ & $\begin{array}{l}\text { NAD recovered } \\
(\mu \text { moles } / g . \\
\text { dry wt. })\end{array}$ \\
\hline $1 \cdot 0$ & 222 & 0.8 & $3 \cdot 74$ \\
\hline 0.5 & 111 & $1 \cdot 2$ & 3.79 \\
\hline 0.25 & $55 \cdot 5$ & $1 \cdot 7$ & 3.59 \\
\hline $0 \cdot 15$ & $\mathbf{3 3} \cdot \mathbf{3}$ & $2 \cdot 8$ & $1 \cdot 74$ \\
\hline
\end{tabular}

Suspensions of Saccharomyces cerevisiae (3 ml.) in a final volume of $4.5 \mathrm{ml}$. were extracted and the NAD assayed spectrophotometrically as described under 'Methods'.

\section{Estimation of nicotinamide coenzymes}

Spectrophotometric method. The coenzymes were reduced enzymically (NAD with alcohol dehydrogenase, NADP with glucose-6-phosphate dehydrogenase), and the amount of coenzyme in the sample calculated from the increase in $E_{340}$ and the molar extinction coefficient for $\mathrm{NAD}(\mathrm{P}) \mathrm{H}\left(6.22 \times 10^{3}\right.$; P-L Biochemicals, 1961). The spectrophotometer used was a Unicam SP 500 (Unicam Instruments, Cambridge, England). The cuvettes used were glass, with a $1 \mathrm{~cm}$. light-path.

The NAD assay system consisted of $1.0 \mathrm{ml}$. extract, $2 \cdot 0 \mathrm{ml}$. pyrophosphate + semicarbazide buffer (Bonnichsen, 1962) $+10 \mu$ l. M-ethanol. After determination of the initial $E_{340}, 10 \mu$ l. alcohol dehydrogenase (stock enzyme, diluted 10-fold with pyrophosphate + semicarbazide buffer) was added. The reaction was usually complete in $5 \mathrm{~min}$; ; the final $E_{340}$ value determined $10 \mathrm{~min}$. after addition of the enzyme.

The NADP assay system consisted of 1-3 ml. extract, $50 \mathrm{~mm}$ tris buffer ( $\mathrm{pH} \mathrm{8 \cdot 3}$ ), to $3.0 \mathrm{ml} .+10 \mu \mathrm{l} .0 \cdot 1 \mathrm{M}$-glucose-6-phosphate. After determination of the initial $\boldsymbol{E}_{\mathbf{3 4 0}}$ value, $10 \mu \mathrm{l}$. glucose-6-phosphate dehydrogenase (stock enzyme, diluted 10-fold in 
$0 \cdot 4 \mathrm{M}$ triethanolamine buffer ( $\mathrm{pH} 7 \cdot 6$; Hohorst, 1962) was added. In this case, the reaction was a little slower; the final $E_{340}$ value was determined $15 \mathrm{~min}$. after the addition of enzyme.

Fluorimetric assay. NAD and NADP were also assayed fluorimetrically by following the increase in fluorescence produced by the reduction of $\mathrm{NAD}(\mathrm{P})^{+}$. The assay systems were the same as those used in the spectrophotometric assays, except that the total volume in the assay tubes was increased to $5.0 \mathrm{ml}$. by the addition of buffer and the amount of extract used was decreased to $0.02-0.1 \mathrm{ml}$. The fluorimeter used was that described by Dalziel (1962). Readings were taken directly from

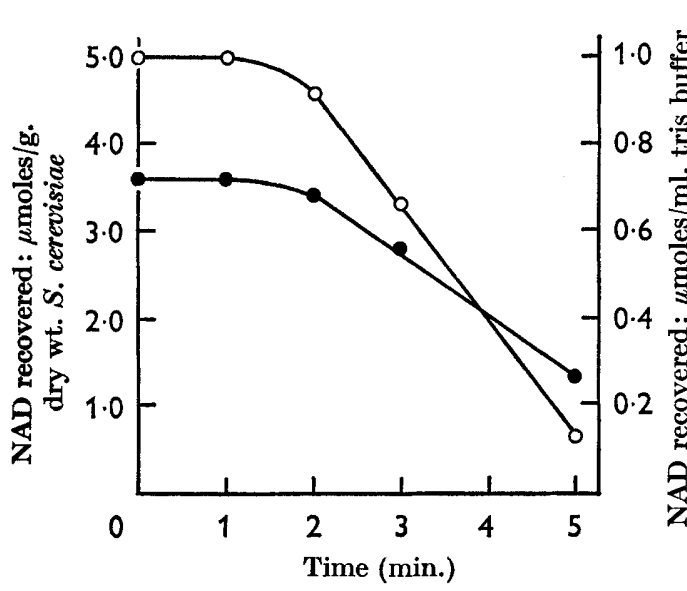

Fig. 1

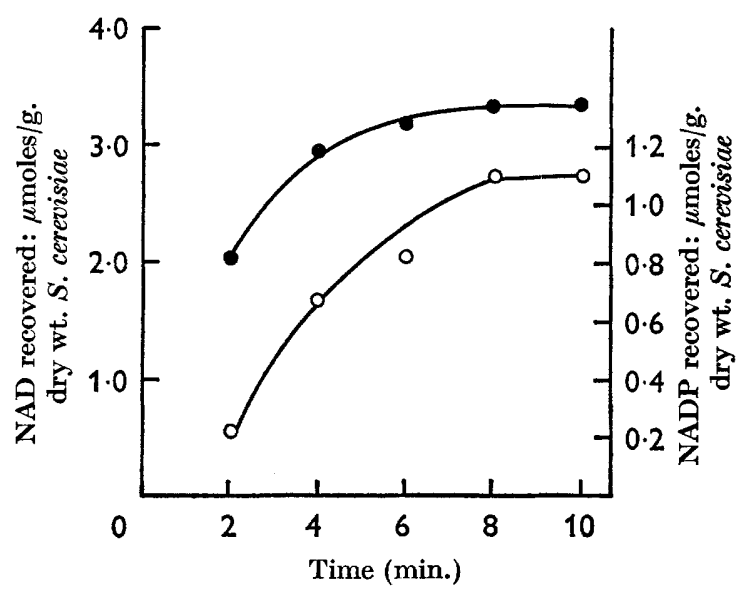

Fig. 2

Fig. 1. Destruction of NAD during extraction in boiling water bath. $3 \mathrm{ml}$. samples of 0.72 mM-NAD in tris buffer, $\mathrm{pH} 8.2 ;(0-\mathrm{O}-\mathrm{O}): 3 \mathrm{ml}$. samples of a suspension (25.0 mg. dry wt./ml.) of Saccharomyces cerevisiae in tris buffer, pH $8.2+1.5 \mathrm{ml}$. $0.33 \mathrm{~N}-\mathrm{HCl}$ heated in boiling water bath. (-O). Extracts neutralized and NAD assayed spectrophotometrically.

Fig. 2. Progress curve of extraction of NAD and NADP from Saccharomyces cerevisiae at $50^{\circ} .3 \mathrm{ml}$. samples of a suspension $(25.0 \mathrm{mg}$. dry wt. $/ \mathrm{ml}$.) of $S$. cerevisiae in tris buffer, pH $8 \cdot 2+1 \cdot 5 \mathrm{ml}$. $0 \cdot 33 \mathrm{~N}-\mathrm{HCl}$ extracted at $50^{\circ}$. Extracts neutralized and NAD $(-O)$ and NADP $(O-O-O)$ assayed spectrophotometrically.

the millivoltmeter on the Vibron amplifier; the recorder was used only to indicate when the reaction was complete. The extracts varied considerably in their quenching properties and in inherent fluorescence. Increase in fluorescence was related to the quantity of $\mathrm{NAD}(\mathrm{P})$ present by addition of a known quantity of $\mathrm{NAD}(\mathrm{P})^{+}$as an internal standard.

\section{RESULTS}

Although the oxidized and reduced forms of the coenzymes were isolated and estimated separately, no significance was attached to the relative proportions of the two forms. The quantities of $\mathrm{NAD}(\mathrm{P})$ quoted refer to the sums of oxidized and reduced forms.

Survey of coenzyme concentrations. The results of a survey of NAD and NADP concentrations in various micro-organisms are given in Table 2. The bacteria studied apparently fall into three groups with respect to NAD concentration. No 


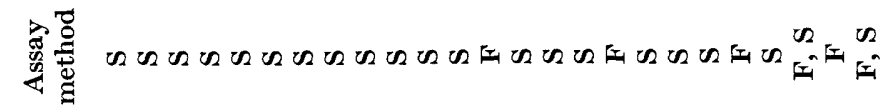

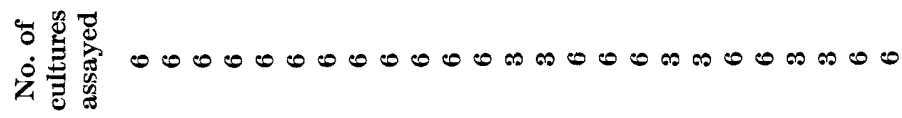

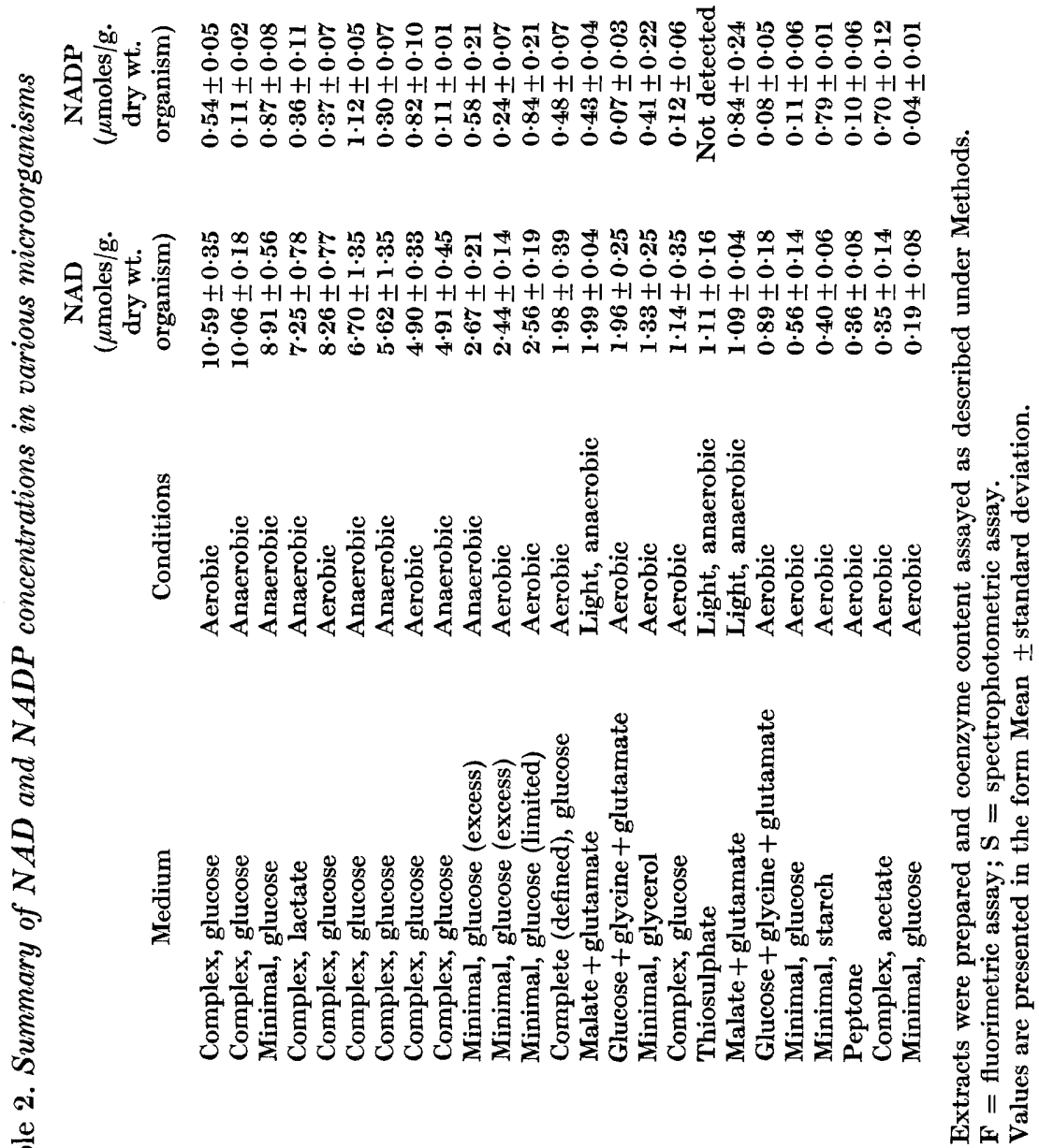

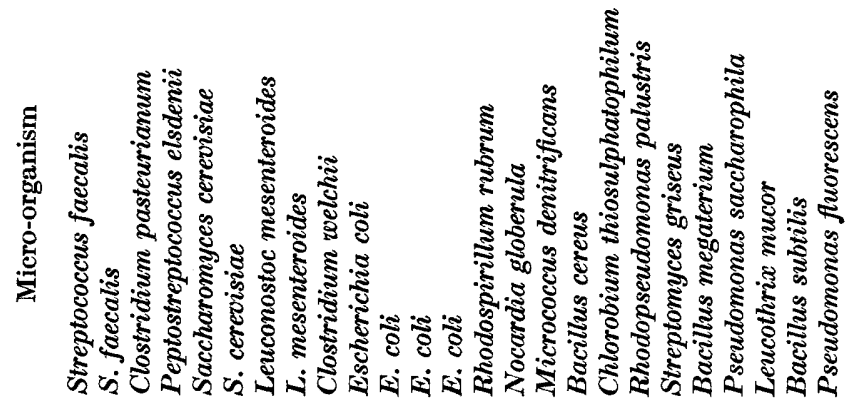


similar tendencies were observed with respect to NADP. The strict anaerobes and lactic acid bacteria had high concentrations of NAD (above $4.5 \mu \mathrm{moles} / \mathrm{g}$. dry weight). The faculative anaerobes had concentrations of between $1 \cdot 0$ and $3 \cdot 0 \mu$ moles/ g. dry weight and the strict aerobes had, with one exception (Nocardia globerula), less than $1.0 \mu \mathrm{mole} / \mathrm{g}$. dry weight. The three photosynthetic bacteria have NAD concentrations similar to those of the faculative anaerobes. Saccharomyces cerevisiae, which is metabolically a facultative anaerobe, had much higher concentrations of NAD than the bacteria of this physiological type.

Table 3. Effect of anaerobiosis on $N A D(P)$ concentrations

Extracts were prepared and coenzyme concentrations measured spectrophotometrically as described under Methods. All cultures (six of each organism) were grown with glucose as substrate.

\begin{tabular}{|c|c|c|c|c|c|}
\hline \multirow[b]{3}{*}{ Organism } & \multirow[b]{3}{*}{ Medium } & \multicolumn{2}{|c|}{ Aerobic } & \multicolumn{2}{|c|}{ Anaerobic } \\
\hline & & $\begin{array}{l}\text { NAD } \\
\text { ( } \mu \text { moles/g } \\
\text { organ }\end{array}$ & $\begin{array}{l}\text { NADP } \\
\text { dry wt. } \\
\text { ism) }\end{array}$ & $\begin{array}{l}\text { NAD } \\
(\mu \text { moles } / g \\
\text { orgar }\end{array}$ & $\begin{array}{l}\text { NADP } \\
\text { dry wt. } \\
\text { ism) }\end{array}$ \\
\hline & & & & & \\
\hline Streptococcus faecalis & Complex & $10 \cdot 59 \pm 0 \cdot 35$ & $0.54 \pm 0.05$ & $10 \cdot 06 \pm 0 \cdot 18$ & $0 \cdot 11 \pm 0.02$ \\
\hline Leuconostoc mesenteroides & Complex & $4 \cdot 90 \pm 0 \cdot 33$ & $0 \cdot 82 \pm 0 \cdot 10$ & $5 \cdot 62 \pm 1 \cdot 35$ & $0.30 \pm 0.07$ \\
\hline Escherichia coli & Minimal & $2 \cdot 44 \pm 0 \cdot 14$ & $0.24 \pm 0.07$ & $2 \cdot 67 \pm 0 \cdot 21$ & $0.58 \pm 0 \cdot 21$ \\
\hline Saccharomyces cerevisiae & Minimal & $4 \cdot 92 \pm 1 \cdot 27$ & $0 \cdot 27 \pm 0 \cdot 08$ & $6 \cdot 47 \pm 1 \cdot 12$ & $0 \cdot 31 \pm 0 \cdot 05$ \\
\hline S. cerevisiae & Complex & $8 \cdot 26 \pm 0.77$ & $0.37 \pm 0.07$ & $6 \cdot 70 \pm 1 \cdot 35$ & $1 \cdot 12 \pm 0 \cdot 05$ \\
\hline
\end{tabular}

Table 4. Effect of complex medium on $N A D(P)$ concentrations

All cultures were grown aerobically. Extracts were prepared and coenzyme levels assayed as described under Methods. Coenzymes were assayed fluorimetrically in Bacillus megaterium (minimal medium). In all other cases they were assayed spectrophotometrically.

\begin{tabular}{|c|c|c|c|c|}
\hline & Minima & nedium & Compl & medium \\
\hline & NAD & NADP & NAD & NADP \\
\hline & & ( $\mu$ moles/g. d & wt. organism & \\
\hline globerula & $1.96+0.25$ & $0.07+0.03$ & $5 \cdot 23+0.52$ & $0.55+0.10^{*}$ \\
\hline yces griseus & $0.89 \pm 0.18$ & $0.08 \pm 0.05$ & $2 \cdot 28 \pm 0 \cdot 10$ & $0.18 \pm 0.06^{*}$ \\
\hline megaterium & $0.56 \pm 0.14$ & $0.11 \pm 0.06$ & $1.52 \pm 0.40$ & $0.24 \pm 0.11 \dagger$ \\
\hline nonas fluorescens & $0.27 \pm 0.07$ & $0.03 \pm 0.01$ & $0.07 \pm 0.02$ & $0.03 \pm 0.01$ \\
\hline
\end{tabular}

* Grown on PMG medium; $\uparrow$ grown on minimal medium $+0 \cdot 1 \%$ yeast extract; $\ddagger$ grown on PM-succinate.

Effect of conditions of growth on coenzyme concentration. The results of studies on the effect of anaerobiosis on $\mathrm{NAD}(\mathrm{P})$ concentration are summarized in Table 3. These results indicate that NAD concentration might differ between cultures grown aerobically and anaerobically, but no particular trend is discernible. NADP concentrations in Streptococcus faecalis and Leuconostoc mesenteroides were higher when the bacteria were grown aerobically than when they were grown anaerobically. This may reflect a greater use of the pentose phosphate pathway under aerobic conditions.

It was found with Escherichia coli that the addition of nicotinic acid (1.5 mg./l.) to minimal medium led to an increase in both NAD and NADP (NAD from 
$\mathbf{2 \cdot 4 4} \mu \mathrm{moles} / \mathrm{g}$. to $\mathbf{9 \cdot 4 4} \mu \mathrm{moles} / \mathrm{g}$.; NADP from $\mathbf{0 . 2 4} \mu \mathrm{moles} / \mathrm{g}$. to $0 \cdot 45 \mu \mathrm{moles} / \mathrm{g}$.). With Bacillus megaterium the addition of $0.1 \%$ yeast extract to minimal medium led to a 2-fold increase in NAD and NAD(P) (Table 4). NAD in Nocardia globerula and Streptomyces griseus was increased 2- to 3-fold on complex media, compared with the amounts found on minimal medium (Table 4). These increased amounts were not found when Pseudomonas fluorescens was grown on a complex medium. The effects on $\mathrm{NAD}(\mathrm{P})$ of growing Saccharomyces cerevisiae on complex and minimal media are shown in Table 3. Concentrations of NAD and NADP were generally lower when the organism was grown on a minimal medium than when it was grown on a complex one. The effects of growing $\boldsymbol{E}$. coli under different conditions are shown in Table 2. It is not possible to detect any differences in $\mathrm{NAD}(\mathrm{P})$ concentration between $\boldsymbol{E}$. coli grown in a completely defined medium with excess glucose and on a minimal medium with excess glucose, or between growth on a minimal medium with excess or with limiting glucose.

\section{Table 5. Effect of energy source on $N A D(P)$ concentration}

\begin{tabular}{|c|c|c|c|c|c|}
\hline \multirow[b]{2}{*}{ Organism } & \multirow[b]{2}{*}{ Substrate } & $\overbrace{}^{\text {NAD }}$ & $\overbrace{}^{\text {NADP }}$ & \multirow{2}{*}{$\begin{array}{c}\text { No. of } \\
\text { cultures } \\
\text { assayed }\end{array}$} & \multirow[b]{2}{*}{$\begin{array}{l}\text { Assay } \\
\text { method }\end{array}$} \\
\hline & & \multicolumn{2}{|c|}{ ( $\mu$ moles/g. dry wt. organism) } & & \\
\hline Streptococcus faecalis & Glucose & $10.59 \pm 0.35$ & $0.54 \pm 0.05$ & 6 & $\mathbf{S}$ \\
\hline S. faecalis & Gluconate & $0.66 \pm 0.28$ & $0.24 \pm 0.01$ & 3 & $\mathbf{S}$ \\
\hline Bacillus cereus & Glucose & $1 \cdot 14 \pm 0 \cdot 35$ & $0.12 \pm 0.06$ & 6 & $\mathbf{F}$ \\
\hline B. cereus & Acetate & $1 \cdot 66 \pm 0.28$ & $1.42 \pm 0.36$ & 6 & $\mathbf{F}$ \\
\hline $\begin{array}{l}\text { Pseudomonas } \\
\text { fuorescens }\end{array}$ & Glucose & $0 \cdot 19 \pm 0 \cdot 08$ & $0.04 \pm 0.01$ & 6 & $\mathbf{F}, \mathbf{S}$ \\
\hline P. fluorescens & Succinate & $0.27 \pm 0.07$ & $0.03 \pm 0.01$ & 6 & $\mathbf{F}, \mathbf{S}$ \\
\hline Escherichia coli & Glucose & $2 \cdot 56 \pm 0 \cdot 19$ & $0.84 \pm 0.21$ & 6 & $\mathbf{S}$ \\
\hline E. coli & Succinate & $2 \cdot 13 \pm 0 \cdot 26$ & $0.70 \pm 0.22$ & $\mathbf{9}$ & $\mathbf{S}$ \\
\hline P. oxalaticus & Formate & $3.59 \pm 0.34$ & $0.50 \pm 0.25$ & 6 & $\mathbf{S}$ \\
\hline P. oxalaticus & Oxalate & $2 \cdot 20 \pm 0 \cdot 37$ & $0.87 \pm 0.18$ & 6 & $\mathbf{S}$ \\
\hline$P$. oxalaticus & Acetate & $0.27 \pm 0.07$ & $0.41 \pm 0.12$ & 6 & $\mathbf{S}$ \\
\hline
\end{tabular}

Some effects of substrate on $\mathrm{NAD}(\mathrm{P})$ concentrations are shown in Table 5. The NAD in gluconate-grown Streptococcus faecalis was about 16 times less than that found in glucose-grown organisms. The NAD found in gluconate-grown organisms is characteristic of a strict aerobe. When Pseudomonas oxalaticus was grown on acetate the NAD concentration was low, as would be expected of a strict aerobe; growth on formate results in a 13- to 14-fold increase, and on oxalate in an 8-fold increase in NAD over the concentration found in acetate-grown $\boldsymbol{P}$. oxalaticus. The differences in NAD concentrations between glucose-grown and acetate-grown Escherichia coli or P. fluorescens are not significant. Only in the case of Bacillus cereus, where growth on acetate caused a 12 -fold increase in NADP, was there any difference in NADP concentrations. 


\section{DISCUSSION}

One of the objects of the work described here was to confirm and extend the work of Kaplan (1960) and Takebe \& Kitahara (1963). The concentrations of NAD and NADP found by these authors are compared with those found in the present work in Table 6. In the case of the lactic acid bacteria, agreement between the values for NAD concentration of Takebe \& Kitahara (1963) and those reported here is close. The amounts of NAD found by Takebe \& Kitahara (1963) in Saccharomyces cerevisiae and Escherichia coli are lower, while their figures for Bacillus subtilis and Pseudomonas fluorescens are higher. The higher values might reflect the fact that these authors grew all their cultures on complex media. Comparison with the results of Kaplan (1960) is less easy, because his $\mathrm{NAD}(\mathrm{P})^{+}$concentrations are expressed as $\mu \mathrm{g} . / \mathrm{g}$. wet weight, and because his bacterial extracts contained variable proportions of an unknown material other than $\mathrm{NAD}^{+}$or $\mathrm{NADP}^{+}$which reacted as oxidized nicotinamide nucleotide in his assay system; in addition, the method of extraction and assay was not described. Nevertheless, the concentrations of NAD found by Kaplan in four facultative anaerobes are of the same order as those reported here, as are the values for the strict aerobes. There is also good agreement between Kaplan and Takebe \& Kitahara for the NAD concentration in Saccharomyces cerevisiae. In general, agreement between the different values reported for NADP concentrations is poor.

Table 6. Comparison of $N A D(P)$ concentrations with results of other authors

\begin{tabular}{|c|c|c|c|c|c|c|}
\hline \multirow[b]{4}{*}{ Streptococcus faecalis } & \multicolumn{2}{|c|}{ Present paper } & \multicolumn{2}{|c|}{$\begin{array}{c}\text { Takebe \& Kitahara } \\
(\mathbf{1 9 6 3})^{*}\end{array}$} & \multicolumn{2}{|c|}{$\begin{array}{l}\text { Kaplan } \\
(1960)^{*}\end{array}$} \\
\hline & NAD & NADP & NAD & NADP & NAD & NADP \\
\hline & \multicolumn{6}{|c|}{$\mu$ moles/g. dry wt. organism } \\
\hline & $10 \cdot 57$ & $0 \cdot 11$ & $10-06$ & $\mathbf{0 \cdot 2 0}$ & • & . \\
\hline Leuconostoc mesenteroides & $5 \cdot 62$ & $\mathbf{0} \cdot 32$ & $4 \cdot 86-5 \cdot 39$ & $0.53-0.70$ & - & - \\
\hline Saccharomyces cerevisiae & $6 \cdot 70$ & $1 \cdot 12$ & $2 \cdot 68-3 \cdot 20$ & $0 \cdot 40-1 \cdot 13$ & $\mathbf{2 \cdot 9}$ & $0 \cdot 4$ \\
\hline Escherichia coli & $2 \cdot 67-1 \cdot 98$ & $0 \cdot 24-0 \cdot 84$ & $1 \cdot 65$ & $0 \cdot 20$ & $1 \cdot 4$ & $0 \cdot 2$ \\
\hline Aerobacter aerogenes & . & . & $2 \cdot 04$ & $0 \cdot 05$ & $\mathbf{2 \cdot 0}$ & $0 \cdot 2$ \\
\hline Achromobacter fischeri & . & . & . & . & $\mathbf{2} \cdot \mathbf{2}$ & $\mathbf{0 \cdot 3}$ \\
\hline Proteus vulgaris & . & - & . & - & $\mathbf{1} \cdot \mathbf{9}$ & $0 \cdot 2$ \\
\hline Pseudomonas fluorescens & $0 \cdot 19$ & $0 \cdot 04$ & $1 \cdot 35$ & $\mathbf{0 \cdot 2 6}$ & $0 \cdot 2$ & $\mathbf{0 \cdot 3}$ \\
\hline Bacillus subtilis & $0 \cdot 35$ & $0 \cdot 70$ & 1.50 & $0 \cdot 17$ & - & - \\
\hline Azotobacter agile & . & . & . & · & $0 \cdot 6$ & $\mathbf{0}$ \\
\hline Mycobacterium butyricum & . & . & - & - & $0 \cdot 5$ & $\mathbf{0}$ \\
\hline
\end{tabular}

* The values of Takebe \& Kitahara (1963) were originally expressed as mg./g. dry wt. organism. Those of Kaplan (1960) were expressed as $\mu \mathrm{g}$./g. wet weight. They have been converted to dry weight values on the assumption that the dry weight content of wet bacterial paste is $20 \%$.

These observations have been extended to show that the strict anaerobes and the Lactobacillaceae (which, though microaerophilic, have a strictly fermentative metabolism), the faculative anaerobes, and the strict aerobes, fall into distinct classes with respect to NAD concentration. There are two exceptions to this generalization. Saccharomyces cerevisiae, a faculative anaerobe, had NAD concentrations more typical of a strict anaerobe, and Nocardia globerula, a strict aerobe, had NAD concentrations as high as many facultative anaerobes. 
The high NAD concentration found in the strict anaerobes seems to be associated with the absence of a haem-linked oxidation system. It was shown by Takebe, Shirakawa \& Kitahara (1964) that in Leuconostoc mesenteroides at least $96 \%$ of the NAD remained in the supernatant fluid after a sonic extract had been centrifuged at $100,000 \mathrm{~g}$ for $60 \mathrm{~min}$. If the very small amount of NAD found here in strict aerobes was closely associated with the intracytoplasmic membrane, as the respiratory enzymes are in Azotobacter agilis (Pangborn, Marr \& Robrish, 1962), and if most oxido-reduction reactions occurred close to the membrane, then the turnover of NAD could be very rapid and the effective concentration of NAD could be as high as it is in strict anaerobes.

Another object of the present work was to determine whether the concentration of NAD or NADP might vary with the conditions of cultivation. Takebe \& Kitahara (1963) showed that NADP concentrations were generally higher in members of the Lactobacillaceae with a heterolactic fermentation pattern than those with a homolactic pattern. They suggested that this might be a reflexion of the greater utilization of the NADP-linked dehydrogenases of the pentose phosphate pathway in these organisms. Although NADP concentrations are in general at the limit of detection by the method used, it is possible to show that in Streptococcus faecalis growing on glucose there is a 3- to 5-fold increase in NADP in aerated cultures over the value in cultures grown under nitrogen. It is possible that under aeration there is an increased utilization of the pentose phosphate pathway in Streptococcus faecalis. This explanation cannot account for the similar increase in NADP found in Leuconostoc mesenteroides. In this organism the glucose-6-phosphate dehydrogenase reacts with both NAD and NADP, and 6-phosphogluconate dehydrogenase with NAD only (De Moss, 1955) and it has been shown (Kemp \& Rose, 1964) that the hydrogen carrier for the reductive reactions of fermentation is NAD. It has not been possible to show any other consistent effects of aeration versus anaerobiosis or of minimal medium versus complex medium on $\mathrm{NAD}(\mathrm{P})$ concentrations.

The nature of the medium has been shown to have a considerable effect on NAD concentration. The addition of nicotinate $(1.5 \mathrm{mg}$./1.) to a minimal medium caused a 4-fold increase in the NAD concentration in Escherichia coli and the addition of $0.1 \%$ yeast extract to a minimal medium led to a 2 - to 3 -fold increase in NAD concentration in Bacillus megaterium. In Nocardia globerula and Streptomyces griseus NAD after growth on complex media was 2-3 times higher than after growth on a minimal medium; NAD in Pseudomonas fuorescens was, in contrast, scarcely affected.

The nature of the carbon source may also affect NAD concentration. The dramatic decrease in NAD in gluconate-grown Streptococcus faecalis as compared with the value when the organism was grown on glucose was probably connected with the change-over from use of the glycolytic pathway in glucose-grown organisms to the ketogluconate pathway in gluconate-grown organisms (Gibbs, Sokatch \& Gunsalus, 1955; Sokatch \& Gunsalus, 1957).

The increased NAD concentration in Pseudomonas oxalaticus grown on formate may be explained by the fact that on formate the organism gains all its energy from the NAD-linked oxidation of formate, and that NADH is the reductant used in the reductive pentose phosphate cycle from which the biosynthetic pathways of the organism diverge(ProfessorJ.R. Quayle, personal communication). The concentration 
of NAD in oxalate-grown $P$. oxalaticus was some 8 times the value for acetate-grown organisms. During growth on oxalate the organism is still dependent on NAD-linked formate oxidation for its entire energy supply (Johnson et al. 1964), but the reducing agent in the early stages of biosynthesis is reduced NADP (Quayle, Keech \& Taylor, 1961). This may account for the slightly higher concentration of NADP in oxalate-grown $\boldsymbol{P}$. oxalaticus. In cases where growth on a different substrate did not induce a new catabolic pathway, as with $P$. fluorescens or Escherichia coli growing on glucose or succinate, $\mathrm{NAD}(\mathrm{P})$ concentration did not change.

The authors wish to thank Professor S. R. Elsden for his advice and encouragement, Miss J. Gibbon and Miss M. A. Whitter for help in growing cultures of Chlorobium thiosulphatophilum and Pseudomonas oxalaticus respectively, and $\mathrm{Mr}$ A. A. Hancock and Mr R. Bacon for technical assistance. The work was done whilst J.L. held a Postdoctoral Fellowship from the U.S. National Institutes of Health. The work was partly supported by the Rockefeller Foundation.

\section{REFERENCES}

Barton-Wright, E. C. (1946). In Practical Methods for the Microbiological Assay of the Vitamin B Complex and Essential Amino Acids. London: Ashe Laboratories.

Bassham, J. A., Birt, L. M., Hems, R. \& Loening, U. E. (1959). Determination of the reduced and oxidized pyridine nucleotides in animal tissues. Biochem. J. 73, 491.

Bauchop, T. \& Elsden, S. R. (1960). The growth of micro-organisms in relation to their energy supply. J. gen. Microbiol. 23, 457 .

Bonnichsen, R. (1962). In Methoden der enzymatischen Analyse. Ed. by H.-U. Bergmeyer, p. 285. Weinheim, German Federal Republic: Verlag Chemie.

BRock, T. D. (1964). Knots in Leucothrix mucor. Science, 144, 870.

Carnahan, J. E. \& Castle, J. E. (1958). Some requirements of biological nitrogen fixation. J. Bact. 75, 121.

Dalziel, K. (1962). Kinetic studies of liver alcohol dehydrogenase. Biochem. J. 84, 244.

De Moss, R. D. (1955). Glucose-6-phosphate and 6-phospho-gluconate dehydrogenases from Leuconostoc mesenteroides. Meth. Enzymol. 1, 238.

Grbis, M., Sokatch, J. T. \& Gunsalus, I. C. (1955). Product labeling of glucose-1-C ${ }^{14}$ fermentation by homofermentative and heterofermentative lactic acid bacteria. $J$. Bact. 70, 573.

Greenbaum, A. L., Clark, J. B. \& McLean, P. (1965). The estimation of the oxidized and reduced forms of the nicotinamide nucleotides. Biochem. $J .95,161$.

HoARE, D. S. (1963). The photo-assimilation of acetate by Rhodospirillum rubrum. Biochem. J. 87, 284.

Hоновsт, H.-J. (1962). In Methoden der enzymatischen Analyse. Ed. by H.-U. Bergmeyer, p. 134. Weinheim, German Federal Republic: Verlag Chemie.

HollaND, I. B. (1961). The purification and properties of megacin, a bactenocin from Bacillus megaterium. Ph.D. Thesis, University of Sheffield.

Jensen, H. L. \& Spencer, D. (1947). The influence of molybdenum and germanium on nitrogen fixation by Clostridium butyricum. Proc. Linnean Soc., N.S.W., 72, 73.

Johnson, P. A., Jones-Mortimer, M. C. \& Quayle, J. R. (1964). Use of a purified bacterial formate dehydrogenase for the micro-estimation of formate. Biochim. biophys. Acta, 89, 351.

KaPlan, N. O. (1960). In The Enzymes. Ed. by P. D. Boyer, H. Lardy \& K. Myrbäck, vol. 3, p. 105. New York, N.Y., U.S.A.: Academic Press Inc.

Kemp, R. G. \& Rose, I. A. (1964). Coupling of reduced pyridine nucleotide in Leuconostoc mesenteroides. J. biol. Chem. 239, 2998. 
Kornberg, H. L. (1958). The metabolism of $\mathrm{C}_{2}$ compounds in micro-organisms. 1. The incorporation of $\left[2-{ }^{14} \mathrm{C}\right]-{ }^{2}$ acetate by Pseudomonas fluorescens and by a Corynebacterium, grown on ammonium acetate. Biochem. J. 68, 535.

Kornberg, H. L., Collins, J. F. \& Bigley, D. (1960). The influence of growth substrates on metabolic pathways in Micrococcus denitrificans. Biochim. biophys. Acta, 39, 9.

Krebs, H. A. \& Bellamy, D. (1960). The interconversion of glutamic acid and aspartic acid in respiring tissues. Biochem. $J .75,523$.

LARSEN, H. (1952). On the culture and general physiology of the green sulfur bacteria. J. Bact. 64, 187.

LAscelles, J. (1959). Adaptation to form bacteriochlorophyll in Rhodopseudomonas spheroides: change in activity of enzymes concerned in pyrrole synthesis. Biochem. $J$. 72, 508.

Lovenberg, W., Buchanan, B. B. \& Rabinowitz, J. C. (1963). The chemical nature of clostridial ferredoxin. J. biol. Chem. 238, 3899.

Mencher, J. M. \& Herm, A. H. (1962). Melanin biosynthesis by Streptomyces lavendulae. J. gen. Microbiol. 28, 665.

P-L Biochemicals (1961). Ultra-Violet Absorption Spectra of Pyridine Nucleotide Coenzymes and Coenzyme Analogues. Milwaukee, Wis., U.S.A.: Pabst Laboratories.

Pangborn, J., Marr, A. G. \& Robrish, S. A. (1962). Localization of respiratory enzymes in intracytoplasmic membranes of Azotobacter agilis. J. Bact. 84, 669 .

Quayle, J. R., Keech, D. B. \& Taylor, G. A. (1961). Carbon assimilation by Pseudomonas oxalaticus (OXI) 4. Metabolism of oxalate in cell-free extracts of the organism grown on oxalate. Biochem. J. 78, 225.

Roberts, R. B., Cowie, D. B., Abelson, P. H., Bolton, E. T. \& Britten, R. J. (1955). Studies of biosynthesis in Escherichia coli. Publ. Carnegie Instn, no. 607.

Sokatch, J. T. \& Gunsalus, I. C. (1957). Aldonic acid metabolism. 1. Pathway of carbon in an inducible gluconate fermentation by Streptococcus faecalis. J. Bact. 73, 452.

Takebe, I. \& Kitahara, K. (1963). Levels of nicotinamide nucleotide coenzymes in lactic acid bacteria. J. gen. appl. Microbiol. 9, 31.

Takebe, I., Shirakawa, T. \& Kitafara, K. (1964). Quantitative studies of enzyme system of heterolactic fermentation. 1. Some aspects of cytoplasm of Leuconostoc mesenteroides as the site of heterolactic fermentation. J. gen. appl. Microbiol. $10,359$.

WALker, D. J. (1958). The purification and properties of the L-threonine deaminase of the rumen micro-organism LCI. Biochem. J. 69, 524 .

Whitaker, A. M. (1961). The growth of micro-organisms in relation to their energy supply. Ph.D. Thesis, University of Sheffield.

Wickerham, L. J. (1951). Taxonomy of yeasts. Tech. Bull., U.S. Dept. Agric., no. 1029. 